\title{
Diversity and antagonistic potential of marine microbes collected from south-west coast of India
}

\author{
S. Sinimol ${ }^{1}$ A. R. Sarika ${ }^{2}$ (1) A. Jayakumaran Nair ${ }^{1}$
}

Received: 2 September 2015 / Accepted: 14 December 2015/Published online: 31 December 2015

(C) The Author(s) 2015. This article is published with open access at Springerlink.com

\begin{abstract}
The diversity of some of the culturable microorganisms associated with marine flora and fauna collected off Vizhinjam and Mulloor coast of South India was evaluated and their bioactive production potential determined. From a total of 24 bacteria, 4 actinomycetes and 8 fungi isolated from diverse marine sources, five bacterial species-BLM3, BSP2, BCS1, BCS4 and BMA6 showed inhibitory activity against at least one of the tested pathogens viz., Klebsiella pneumonia KU1, Pseudomonas aeruginosa VL3, Salmonella enterica typhimurium MTCC 98, Escherichia coli MTCC 40, Micrococcus luteus MTCC 105, Staphylococcus simulans MTCC 3610, Proteus vulgaris MTCC 426, Vibrio fluvialis, Vibrio sp. P3a and Vibrio sp. P3b. The isolated actinomycetes and fungi did not produce significant inhibition zones against the tested pathogens; however, the macroalgal isolated actinomycetes strain AMA1 produced reddish pigment in Starch Casein medium which remained stable till the stationary phase of growth. The marine sediment isolate BCS4, identified as Bacillus sp. showed wide spectrum of activity against the tested Gram positive bacteria, S. simulans MTCC 3610 and Gram negative bacteria, Proteus vulgaris with zone of inhibitions of 25 and $11 \mathrm{~mm}$ respectively. Better extraction
\end{abstract}

Electronic supplementary material The online version of this article (doi:10.1007/s13205-015-0318-1) contains supplementary material, which is available to authorized users.

A. R. Sarika

sarikaar81@gmail.com

1 Department of Biotechnology, University of Kerala, Kariavattom, Thiruvananthapuram, Kerala 695581, India

2 Kerala State Council for Science, Technology and Environment, Sasthra Bhavan, Pattom, Thiruvananthapuram, Kerala 695004, India of the bioactive compound was obtained with ethyl acetate when compared with methanol, benzene and hexane and TLC analysis revealed the presence of an active compound. The 16SrRNA sequencing confirmed the potent strain belong to Bacillus sp. and hence designated Bacillus sp. BCS4.

Keywords Microbial diversity - Marine microbes · Bioactivity $\cdot$ Bacillus sp. BCS4

\section{Introduction}

The increasing antibiotic resistance pose serious concerns in health sector and necessitates seeking natural alternatives. The marine ecosystem being less explored, have prospects for finding novel bioactive producing microbes. Marine microbes represent a distinctive group of organism owing to their immense genetic (Strobel and Daisy 2003) and biochemical diversity (Rusch et al. 2007) and are rich sources of a large variety of bioactive compounds (Debbab et al. 2010). These originate mainly in sediments but they are also present in open oceans in association with other marine organisms (Supriya and Yogesh 2010). Marine invertebrates and plants, in particular, represent an environment rich in microorganisms that produce compounds with bioactive properties including antibacterial, antifungal, antiviral, anticancer, antifouling and antibiofilm activities (Glöckner et al. 2012). The microbial symbionts were been crucial in the discovery of many bioactive compounds reported earlier. The competition among microbes for space and nutrients is one of the driving forces behind the production of precious antibiotics and other useful pharmaceuticals in the marine environment (Thakur et al. 2005b). Microorganisms associated with

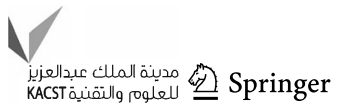


marine invertebrates are proved to be valuable candidates for drug discovery (Jensen and Fenical 2000; Hentschel et al. 2003; Imada 2004; Thakur et al. 2005a).

The marine microbes include cellular life forms such as bacteria, fungi and plankton, along with viruses that free load along with them. The marine bacteria represent one of the hardly untapped sources of potent therapeutic and novel drug leads. The emergence of multidrug resistant bacteria poses a major threat which in turn forces the discovery of new potent drugs to replace the conventional antibiotics. The decline in the discovery of newer antibiotics of the terrestrial origin necessitates exploring new ecological niches most notably the marine. Marine bacteria showing antibacterial activities have been isolated from various biotypes and most frequently isolated strains belong to the genus Bacillus, Micrococcus, Pseudomonas, Vibrio, Flavobacterium, and Alteromonas (Jayanth et al. 2001; Nithya et al. 2011; Eltmany et al. 2014; Marinho et al. 2009; Baranova and Eqorov 1989; Leon et al. 2010). However, a major constraint in the discovery of novel drugs from the marine microbes rely up on the fact that majority of the marine microbes are uncultivable in the laboratory conditions. Nevertheless, using cultivated microorganisms is still the only way to get detailed information about microbial characteristics and processes, thus highlighting the need to further focus on culturing microorganisms and developing better culturing techniques (Glöckner et al. 2012).

Marine microbes are rich and yet less harnessed source of structurally diverse secondary metabolites, many of which possess unique biological activities. The present study attempts to isolate and screen novel bioactive producing microbes from the Vizhinjam and Mullor area of the South-west coast of India, which are known for their rich biodiversity and novel compounds in them.

\section{Materials and methods}

\section{Collection of samples}

The marine samples for the isolation of microorganisms were collected from the Vizhinjam and Mulloor coast of Kerala, India. The geographical position of Vizhinjam coast is Longitude E $76^{\circ} 59^{\prime}$ and Latitude $\mathrm{N} 8^{\circ} 22^{\prime}$.

The samples collected include the Sepia and Crab from the fish landing centre in Vizhinjam coast and Limpets, macroalgae and the sediments from the Mulloor coast. The samples except marine sediments soon after collection were washed with sterile distilled water to remove the soil and brought to the laboratory in sterile polythene bags.
Isolation of associated microbes from the marine samples

The samples viz., crab, sepia and limpets after removing their outer shell and intestine and the macroalgae were crushed. The resultant was serially diluted in normal saline $(0.85 \% \mathrm{NaCl})$ and $0.1 \mathrm{ml}$ spread plated in Zobell Marine Agar (Hi-Media), glucose agar and starch-casein agar to determine the growth of bacteria, fungi and actinomycetes respectively. Similarly, the coastal sediments were serially diluted and plated. The plates were monitored for $48 \mathrm{~h}$ by incubating at $37{ }^{\circ} \mathrm{C}$ for distinct bacterial colonies. The plated glucose agar was incubated at $27 \pm 2{ }^{\circ} \mathrm{C}$ for $48 \mathrm{~h}$ and starch-casein agar at $27 \pm 2{ }^{\circ} \mathrm{C}$ for 5-7 days to examine the growth of marine fungi and actinomycetes respectively. In all the cases, $\mathrm{CFU} / \mathrm{ml}$ was recorded and the morphologically distinct colonies of the bacteria, fungi and actinomycetes were streak plated in respective agar plates to get the auxenic microbial isolate. The pure cultures of the isolates were stored in glycerol stocks at refrigeration temperatures for further studies.

\section{Screening of antibacterial activity of the isolated marine microbes}

The indicator strains used to determine the antibacterial activity of the isolated marine bacteria, fungi and actinomycetes included both the human pathogenic and fish pathogenic bacteria and are listed in Table 1 . The bacterial cultures were stored in agar slants at refrigeration temperatures and were activated in fresh nutrient agar medium as and when required.

The isolated marine bacteria were inoculated on to $10 \mathrm{ml}$ of Zobell Marine Broth and incubated under shaking conditions at $37{ }^{\circ} \mathrm{C}$ for $48 \mathrm{~h}$. After the respective incubation period, $1 \mathrm{ml}$ of sample was withdrawn from the culture flask and centrifuged at 10,000 rpm for $15 \mathrm{~min}$. The pellet was discarded and the supernatant so obtained was filtered using $0.22 \mu \mathrm{m}$ microfilter (Hi-Media). The resultant cell free supernatant was examined for antibacterial activity against the indicator bacterial strains. For determining the antibacterial activity of the fungal isolates and actinomycetes, the strains were inoculated in glucose broth and starch-casein broth and incubated for 5 and 7 days respectively under shaking conditions. The indicator strains were activated in Nutrient Broth (Hi-Media) by incubating the inoculated broth for $24 \mathrm{~h}$ at $37^{\circ} \mathrm{C}$. The antibacterial activity was detected using the well-diffusion method (BSI 1968). The bacterial culture was swabbed on to MuellerHinton agar (Hi-Media) plates. Using a cork borer, wells of $7 \mathrm{~mm}$ diameter was made on the agar plates containing the 
Table 1 Indicator bacterial strains used for screening the antibacterial activity of isolated Marine microorganisms

\begin{tabular}{lll}
\hline Sl. no. & Bacterial strains & Source \\
\hline 1 & Klebsiella pneumoniae KU1 & Clinical isolate \\
2 & Pseudomonas aeruginosa VL3 & Clinical isolate \\
3 & Salmonella enterica typhimurium MTCC 98 & MTCC $^{\text {a }}$ \\
4 & Escherichia coli MTCC 40 & MTCC \\
5 & Micrococcus luteus MTCC 105 & MTCC \\
6 & Staphylococcus simulans MTCC 3610 & MTCC \\
7 & Proteus vulgaris MTCC 426 & MTCC \\
8 & Vibrio fluvalis & Fish pathogen \\
9 & Vibrio sp. P3a & Marine isolate \\
10 & Vibrio sp. P3b & Marine isolate \\
\hline
\end{tabular}

${ }^{a}$ Microbial type culture collection lawn of indicator bacterial strain. The cell free supernatant $(50 \mu \mathrm{l})$ of the marine microbes was added to each well and incubated for $24 \mathrm{~h}$ at $37^{\circ} \mathrm{C}$. The plates were observed for the zones of inhibition around the well and the zone diameter $(\mathrm{mm})$ was recorded.

\section{Determination of growth characteristics of the potent bacterial isolate}

Among the microbes screened for bioactive production, active marine bacterial isolate BCS4 was subjected to determination of growth characteristics for effective extraction of the bioactive compound. The bacterial isolate BCS4 was inoculated in $100 \mathrm{ml}$ Zobell Marine Broth and growth and bioactivity was determined every $24 \mathrm{~h}$ interval for $120 \mathrm{~h}$. The determination of growth was carried out by taking the optical density of the inoculated culture broth at $600 \mathrm{~nm}$ after every $24 \mathrm{~h}$. The bioactivity was determined by assaying the cell-free supernatant against the indicator strains selected by well-diffusion method as described earlier.

\section{Extraction and chemical screening of bioactive compound from the potent isolate}

The potent isolate was inoculated into $100 \mathrm{ml}$ of Zobell Marine Broth and incubated at $37{ }^{\circ} \mathrm{C}$ for $96 \mathrm{~h}$. The culture was then centrifuged at $10,000 \mathrm{rpm}$ for $15 \mathrm{~min}$ and the supernatant filtered. The resultant filtrate was extracted separately with solvents viz., methanol, ethyl acetate, benzene and hexane @ $1 \mathrm{ml} / \mathrm{ml}$ culture supernatant of the marine isolate and dried at room temperature $\left(28 \pm 2{ }^{\circ} \mathrm{C}\right)$; in order to determine the best solvent extraction strategy for this bioactive compound. The well-diffusion assay method was used to determine the bioactivity of the extracted compounds. The solvent which extracted the compound better was used for the further extraction of the bioactive compound.

Thin layer chromatography (TLC) technique was employed to screen the bioactive compound. The crude ethyl acetate extract obtained from Bacillus sp. BCS4 was partially purified by TLC using silica gel coated chromatography plates. In order to determine the best solvent system for effective separation of crude compound, solvents such as ethyl acetate, methanol, chloroform and water were used in the proportions viz., (1) Ethyl acetate:Methanol:Water (20:2.7:2; v/v/v), (2) Ethyl acetate:Methanol:Water (20:2.8:1; v/v/v) and (3) Chloroform:Methanol (9:1; v/v). An aliquot of crude extract was spotted onto the silica gel plate and allowed to dry for a few minutes. Afterwards, the plate was developed with the solvent as mobile phase in the earlier mentioned proportion in a previously saturated glass chamber with eluting solvents for $30 \mathrm{~min}$ at room temperature. The developed plate was dried under normal air and the spots were visualized under visible light. Retention factor (Rf) value of the spot separated on the TLC Plate was determined by adopting the formula,

Rf value $=\frac{\text { Movement of solute from the origin }}{\text { Movement of the solvent from the origin }}$

The TLC plates were observed for distinct bands. The compound was eluted from the developed plate by scrapping off silica gel and mixed well with ethyl acetate and centrifuged for $10 \mathrm{~min}$ at $10,000 \mathrm{rpm}$. The supernatant was subjected to determination of bioactivity using well-diffusion assay against the indicator strain $S$. simulans MTCC3610 and observed for inhibition zone after incubation at $37{ }^{\circ} \mathrm{C}$ for $24 \mathrm{~h}$. 


\section{Molecular characterization of the strain BCS4}

The molecular characterization of the active marine bacterial isolate which showed maximum inhibitory activity against the indicator strains tested were subjected to biochemical and molecular characterization studies based on $16 \mathrm{~S}$ ribosomal RNA sequencing. The total genomic DNA extraction of the active bacteria cultured in Zobell Marine Broth was carried out by Phenol/chloroform extraction method. The 16S rRNA gene of the isolate was amplified using Universal Eubacterial 16S rRNA gene primers and sequenced. The resultant 16S rRNA gene sequence from the potent isolate BCS4 was compared with other bacterial sequences from the GenBank nucleotide database with BLAST (Altschul et al. 1990) to analyse pairwise homology and phylogenetically analyzed using MEGA 6.01 software.

\section{Results}

\section{Isolation of microorganisms from the marine invertebrates, macroalgae and coastal sediments}

The samples from the marine environment (Vizhinjam and Mulloor Coast) used for the isolation of marine bacteria, fungi and actinomycetes include the coastal sediments, marine invertebrates viz., crab, sepia and limpet and the marine macroalgae. The isolated microorganisms from the respective agar plates after spread plating and incubation for $24 \mathrm{~h}$ were streaked to get pure cultures of the same. The bacteria were grown in Zobell Marine Agar medium; the list and source of the isolated bacterial strains are presented in Table 1. The total count of bacteria per $\mathrm{ml}$ of the sample viz., coastal sediments, crab, sepia, limpets and the marine macroalgae was $6.5 \times 10^{6}, 3.2 \times 10^{5}, 5.9 \times 10^{5}, 1.9 \times$ $10^{5}$ and $2.8 \times 10^{4} \mathrm{CFU}$ respectively (Fig. 1).

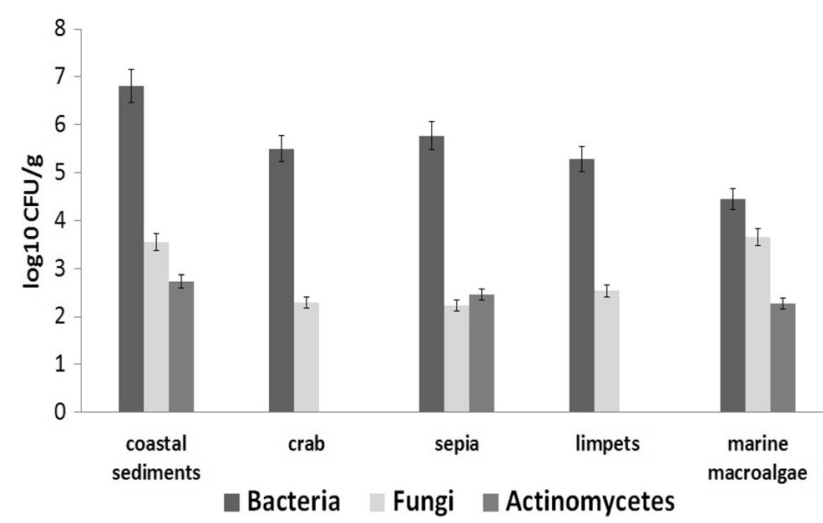

Fig. 1 Marine microbes associated with samples collected off southwest Coast of India
Table 2 The bacterial, fungal and actinomycetes strains isolated from marine samples

\begin{tabular}{|c|c|c|c|}
\hline \multirow[t]{2}{*}{ Marine sample } & \multicolumn{3}{|c|}{ Microbes isolated } \\
\hline & Bacteria & Fungi & Actinomycetes \\
\hline \multirow[t]{4}{*}{ Coastal sediments } & BCS1 & FCS1 & ACS1 \\
\hline & $\mathrm{BCS} 2$ & FCS2 & ACS2 \\
\hline & BCS3 & & \\
\hline & BCS4 & & \\
\hline \multirow[t]{2}{*}{ Crab } & BCB1 & FCB1 & - \\
\hline & BCB2 & FCB2 & \\
\hline \multirow[t]{5}{*}{ Sepia } & BSP1 & FSP1 & ASP1 \\
\hline & BSP2 & FSP2 & ASP2 \\
\hline & BSP3 & FSP3 & \\
\hline & BSP4 & FSP4 & \\
\hline & BSP5 & & \\
\hline \multirow[t]{3}{*}{ Limpets } & BLM1 & FLM1 & - \\
\hline & BLM2 & FLM2 & \\
\hline & BLM3 & & \\
\hline \multirow[t]{9}{*}{ Macroalgae } & BMA1 & FMA1 & AMA1 \\
\hline & BMA2 & FMA2 & AMA2 \\
\hline & BMA3 & & \\
\hline & BMA4 & & \\
\hline & BMA5 & & \\
\hline & BMA6 & & \\
\hline & BMA7 & & \\
\hline & BMA8 & & \\
\hline & BMA9 & & \\
\hline
\end{tabular}

The actinomycetes isolated from different samples in starch-casein agar plates after spread plating and incubation for 7 days were streaked onto fresh starch-casein agar plates for getting pure culture of the same. The isolated actinomycetes from different marine sources are given in Table 2. The macroalgal isolate AMA2 produced a pigmented colony upon incubation which yielded a red coloured pigmentation in the starch casein agar plate as well in the culture broth up on 7 days incubation. The total count of actinomycetes per $\mathrm{ml}$ of the sample viz., coastal sediments, crab, sepia, limpets and the marine macroalgae was $5.5 \times 10^{2}, 0,2.9 \times 10^{2}, 0$ and $1.9 \times 10^{2} \mathrm{CFU}$ respectively (Fig. 1).

\section{Screening of antibacterial activity of the isolated marine microorganisms}

Of the 23 bacteria isolated from different marine sources, only five (22\%) bacterial strains viz, BLM3, BSP2, BCS1, BCS4 and BMA6 showed inhibitory activity against at least one of the tested strains when detected by well-diffusion method. The results revealed that the isolate from 
coastal sediments (BCS4) exhibited a broad activity spectrum inhibiting both Gram positive (M. luteus and S. simulans) and Gram negative (Proteus vulgaris and two Vibrio sp. P3a and P3b) bacteria.

The spectrum of inhibitory activity was narrow for the four strains (BLM3, BSP2, BCS1 and BMA6) which inhibited either one of the indicator strains. The coastal sediment isolates BSP1 and BSP4 exhibited $100 \%$ inhibition against the marine Vibrio sp. P3a with zone of inhibition of 25 and $31 \mathrm{~mm}$ respectively. None of the marine actinomycetes and fungal isolates showed inhibitory activity against the tested pathogens. Hence, the bacterial isolate BCS4 which showed the highest bioactivity was subjected to further molecular characterization and elution of antibacterial compound.

The isolated actinomycetes and fungi did not produce significant inhibition zones against the tested pathogens; however, the macroalgal isolated actinomycetes strain AMA1 produced reddish pigment in Starch Casein medium which remained stable till the stationary phase of growth (Fig. 2).

\section{Growth characteristics and bioactive compound production by the bacterial isolate BCS4}

The determination of growth of the potent marine isolate Bacillus sp. BCS4 revealed that the growth initiated after about $8 \mathrm{~h}$ of incubation, entered into the exponential phase after $24 \mathrm{~h}$. The bacterium showed a steady growth till the 96th $\mathrm{h}$ after which it ceased to grow and entered the stationary phase followed by the decline. The steady rise in the growth rate indicated that the production of the metabolites maximized around 48 to $72 \mathrm{~h}$ (Fig. 3). The growth was followed by the production of bioactive metabolite which maximized at the 72th $\mathrm{h}$ of incubation and remained stable till the 96th $\mathrm{h}$ and decreased thereafter.

\section{Solvent extraction of the bioactive compound}

Among the solvents tested for better extraction of the bioactive compound, ethyl acetate extract gave wide zone of inhibition (Table 3) against the test strains indicating the superiority of ethyl acetate over other solvents in extracting the bioactive compound of BCS4 (Fig. 4).

The partial purification and chemical screening of the bioactive compound from the crude ethyl acetate extract was carried out using Thin Layer Chromatography. Distinct band was detected irrespective of the solvent systems, which is indicative of the presence of a compound in the crude extract. The Rf value was measured as $0.60,0.72$ and $0.79 \mathrm{~cm}$ for the solvent systems 1,2 and 3 respectively. The ethyl acetate extracted compound eluted from the silica gel plate gave a zone of inhibition of $27.2 \pm 0.3 \mathrm{~mm}$ against $S$. simulans MTCC 3610 confirming the bioactive potential.

\section{Molecular characterization of the active marine bacterial isolate}

The bacterial strain BCS4 which inhibited majority of the tested pathogens was characterized using 16S rRNA gene sequencing and the obtained sequence (749 bp) was blasted using Megablast tool of GenBank (http://www.ncbi.nlm. nih.gov). The blast results revealed $98 \%$ similarity with the Bacillus sp. alk3. The phylogenetic tree was constructed through Neighbour Joining Method using Mega 6.0 software (Fig. 5). The active marine isolate was characterized as Bacillus sp. and designated Bacillus sp. BCS4.
Fig. 2 Antibacterial activity of Marine bacterial isolates

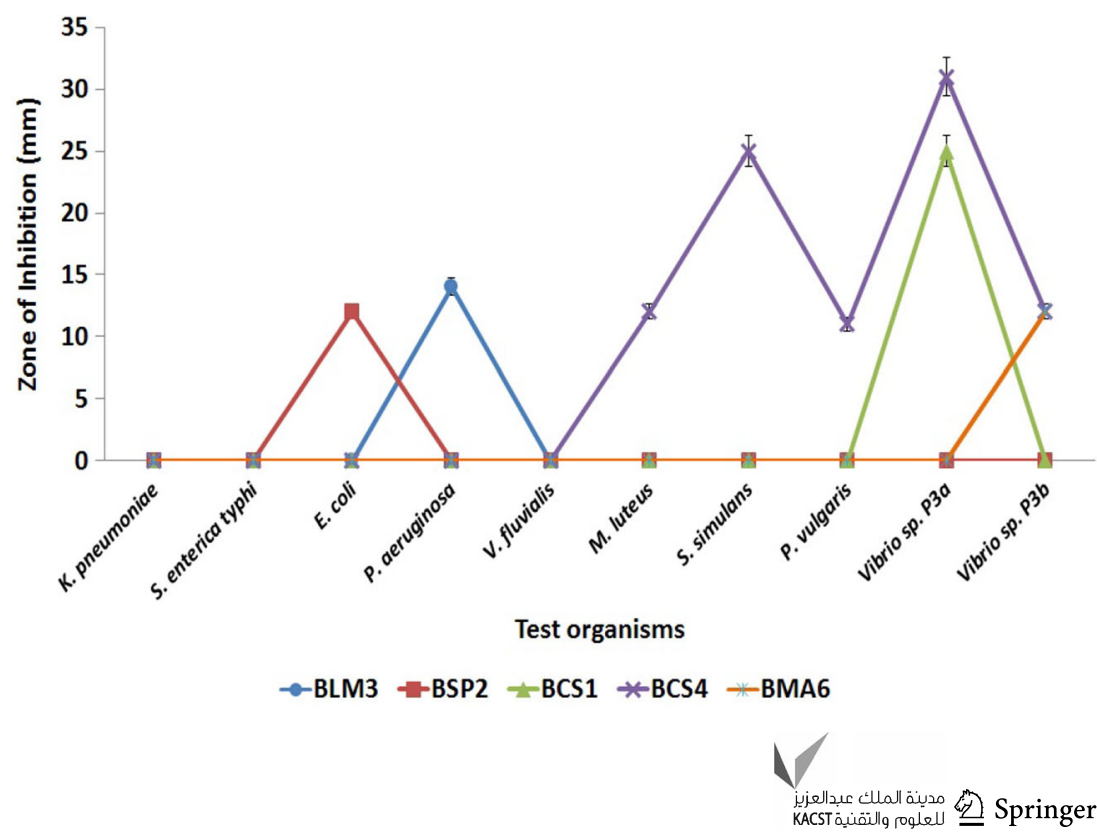


Fig. 3 Growth characteristics andbioactive compound production of Marine bacterial isolate $\mathrm{BCS} 4$

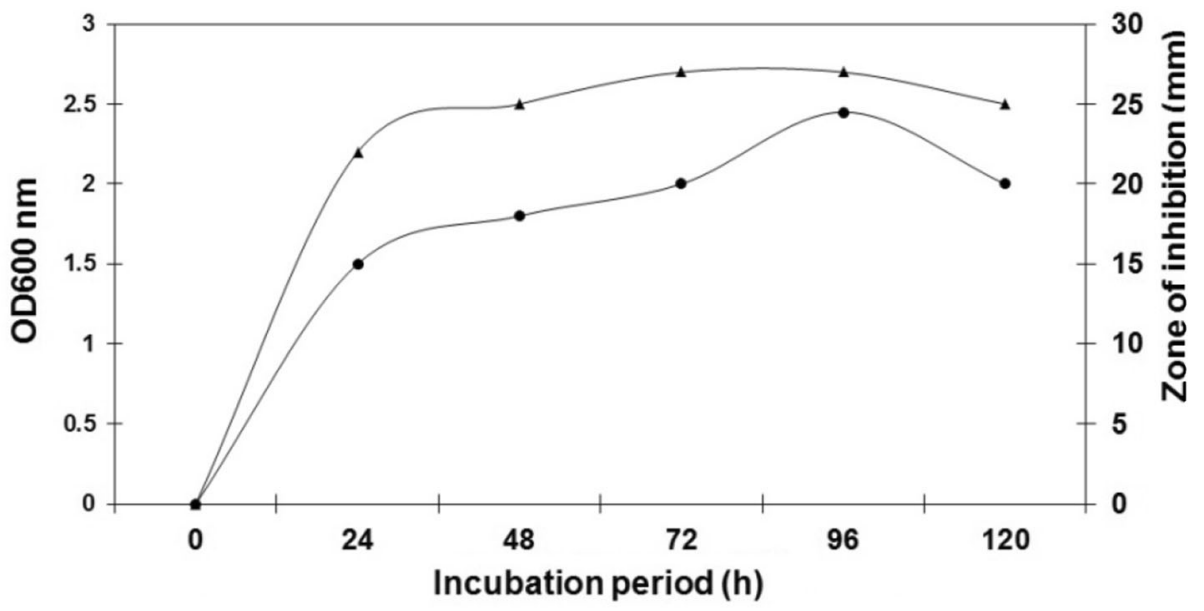

- OD600nm + Inhibtory activity
Table 3 Activity based extraction of the bioactive compound from Bacillus sp. BCS4 using different solvents

\begin{tabular}{lll}
\hline Solvents & \multicolumn{2}{l}{ Zone diameter $(\mathrm{mm})$} \\
\cline { 2 - 3 } & S. simulans & P. vulgaris \\
\hline Methanol + BCS4 & $17.8 \pm 0.3$ & $6.67 \pm 0.6$ \\
Benzene + BCS4 & $13.7 \pm 0.6$ & $6.8 \pm 0.3$ \\
Ethyl acetate + BCS4 & $27.0 \pm 0.3$ & $11.7 \pm 6$ \\
Hexane + BCS4 & - & - \\
Methanol alone & - & - \\
Benzene alone & - & - \\
Ethyl acetate alone & - & - \\
Hexane alone & - & -
\end{tabular}

Well diameter $=5 \mathrm{~mm}$; '-' indicates absence of inhibition zone

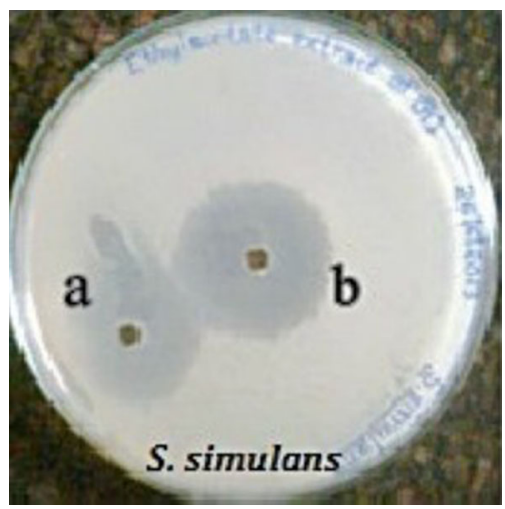

Fig. 4 Zone of antibacterial inhibition of ethyl extract of Bacillus sp. BCS4 against $S$. simulans MTCC3610. a Ethyl acetate extract, b compound eluted from silica gel plate

\section{Discussion}

The marine ecosystem is less harnessed in terms of developing alternative drugs to antibiotics. The rich diversity, along with extreme physical conditions makes marine environment an ideal source for proving novel drug leads. The coasts, Vizhinjam and Mulloor along the southwest coast of India harbour rich and biodiverse flora and fauna with millions of microorganisms associated with it. When compared to the terrestrial counterparts, these flora and fauna and the marine environment, in general possess novel drugs and other chemically diverse bioactives (Delong 2007). Though the percentage of culturable microbes remains too little, these can provide insights into the characteristics and potency of microbes (Glöckner et al. 2012) thriving in such extreme conditions.

The marine microbial biota is rich and diverse. The study on the diversity of microbes from coastal sediments and marine flora and fauna revealed that the percentage of bacteria isolated from the studied marine sources was comparatively higher than actinomycetes and fungi. While no actinomycetes were isolated from limpets and crab, at least two fungal strains were isolated from them. Similar observation was made by Tawiah et al. (2012) for the samples collected from Cape Coast Duakor Sea beach at Gulf of Guinea in which the frequency of bioactive producing bacteria was high compared to actinomycetes and fungi. The results from that study also revealed $27 \%$ antibiotic producing microorganism out of 119 isolated recovered. These observations coincided with the observations of the present study which gave $22 \%$ bioactive producing bacteria. On the contrary, high rate of isolation of antibiotic producers $(70 \%)$ was recorded by O'Brien et al. (2004) from the Amazon basin. 
Fig. 5 Phylogenetic tree drawn in MEGA 6.0 software using Neighbour Joining Method

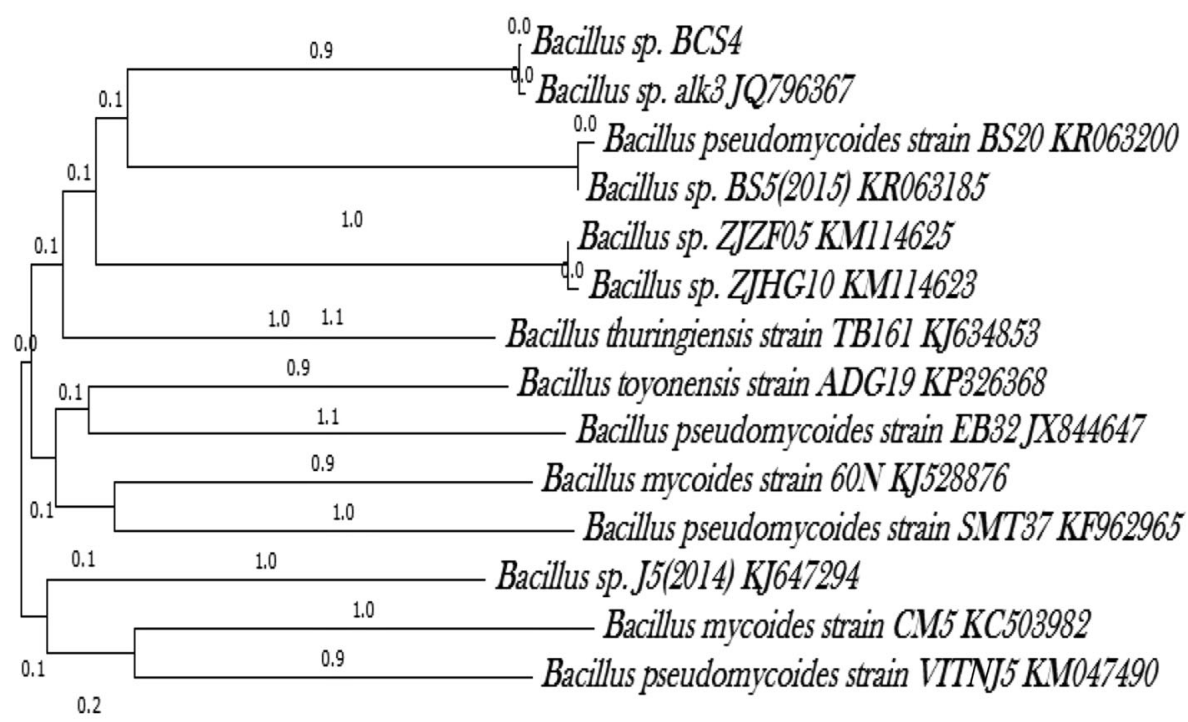

0.2
The highest number of active isolates was obtained from the coastal sediments collected from Vizhinjam coast. The increased number of active isolates in the sediments than from the marine flora and fauna studied might be attributed to fact that the area of sample collection being a Fish Landing area and prone to pollution with fish wastes and other waste discharges, the microbes there might have accustomed to thrive by producing defense compounds. The findings are supported by the observations of Tawiah et al. (2012). The study also revealed active compound producing bacteria and the absence of inhibitory potential by isolated Actinomycetes and Fungi. The absence of the zone of inhibition by the fungal and actinomycetes strains against the tested pathogens might be attributed to the changes in culture conditions or the limitations in the strains tested etc. Further, the actinomycetes and fungi require condition optimization for the production of the bioactive compounds. This would require the standardization of the culture conditions or supplementation with different media components to enrich the medium to enable the production of such compounds. The study carried out Kiranmayi et al. (2011) employed 11 different culture media in order to determine the best production media for the isolated actinomycetes. The variations noted in the antibiotic producers among the isolated strains may also be due to it's dependence on the isolation and assay procedure, test organisms, type of media used and the sources of bacterial isolates (Giudice et al. 2007). A salient finding noted from the present study that the actinomycete strain AMA1 produced a reddish pigment in Starch-Casein medium which remained stable till the stationary phase of growth. Earlier reports evidenced the production of antitumour (Soliev et al. 2011; Olano et al. 2009), antibacterial (Pham et al. 2014) and other commercially important pigments from marine Actinomycetes. Studies also revealed prognosin like pigment production by Actinomycetes of marine origin (Quadri and Asgar 2012; Chaudhary et al. 2013). The studies on production and determination of the nature of the pigment produced by the strain AMA1 are needed further for characterization and evaluating it's applicational potentiality.

The bacterial isolate from coastal sediments (BCS4) exhibited a broad activity spectrum inhibiting both Gram positive (Micrococcus luteus and Staphylococcus simulans) and Gram negative (Proteus vulgaris and two Vibrio sp. P3a and P3b) bacteria. Similar broad activity spectrum was observed with marine Pseudoalteromonas species as was observed by Isnansetyo and Kamei (2003). The activity spectrum observed with the marine isolate in the study provides prospects for a future drug or bioactive lead. The growth pattern of the bacterial isolate revealed that the active metabolite production maximized at the late logarithmic phase (i.e., at the 72th $\mathrm{h}$ of incubation) and remained stable till the 96th $\mathrm{h}$. Similar to this observation, Radhakrishna et al. (2011) noted maximum active metabolite production of sponge isolated Bacillus subtilis MTCC 10619 at the 72th h, which decreased thereafter.

The isolate with potent activity was phylogenetically confirmed as Bacillus sp. BCS4. It is evidenced from the reports of Mondol et al. (2013) that marine Bacillus isolates produce diverse bioactive metabolites with novel modes of action and has potentials for the development of effective management strategies to combat human, animal and phytopathogens in biorational manners. The activity 
spectrum noted for Bacillus sp. BCS4 is indicative of their possible medical and pharmaceutical applications. The compound was effectively extracted using the ethyl acetate solvent and the confirmation of the active compound in TLC provides insights into development of potent drugs out of this compound. Further work to detect the compound chemistry and the purification of the compound to homogeneity is under progress.

Acknowledgments The present research work is part of the first author's M.Sc. dissertation work. The authors thank the authorities of University of Kerala for providing the facilities for carrying out the work.

Conflict of interest The authors declare that they have no conflict of interest.

Open Access This article is distributed under the terms of the Creative Commons Attribution 4.0 International License (http:// creativecommons.org/licenses/by/4.0/), which permits unrestricted use, distribution, and reproduction in any medium, provided you give appropriate credit to the original author(s) and the source, provide a link to the Creative Commons license, and indicate if changes were made.

\section{References}

Altschul SF, Gish W, Miller W, Myers EW, Lipman DJ (1990) Basic local alignment search tool. J Mol Biol 215(3):403-410

Baranova NA, Eqorov NS (1989) Production of antibiotic substances by natural variants of the marine bacterium Vibrio fischeri. Antibiot Khimoter 34(1):7-10

BSI (1968) Methods on microbial examination for dairy purposes. British Standards Institution, British Standards House, London, BS. 4285

Chaudhary HS, Soni B, Shrivastava AR, Shrivastava S (2013) Diversity and versatility of actinomycetes and its role in antibiotic production. J App Phar Sci 3(8 Suppl 1):S83-S94. doi:10.7324/JAPS.2013.38.S14

Debbab A, Aly AH, Lin WH, Proksc P (2010) Bioactive compounds from marine bacteria and fungi. Microb Biotechnol 3(5):544-563. doi:10.1111/j.1751-7915.2010.00179.x

Delong EF (2007) Microbial domains in the ocean: a lesson from the Archae. Oceanography 20(2):124-129. doi:10.5670/oceanog. 2007.56

Eltmany EE, Abdelmohsen UR, Ibrahim AK, Hassanean HA, Hentschel U, Ahmed SA (2014) New antibacterial Xanthone from the marine sponge derived Micrococcus sp. EG45. Bioorg Med Chem Lett 24(21):4939-4942. doi:10.1016/j.bmcl.2014.09. 040.Epub2014Sep22

Giudice AL, Bruni V, Michaud L (2007) Characterization of Antarctic psychrotrophic bacteria with antibacterial activities against terrestrial microorganisms. J Basic Microbiol 47:496-505

Glöckner FO, Stal LJ, Sandaa R-A, Gasol JM, O'Gara F, Hernandez F, Labrenz M, Stoica E, Varela MM, Bordalo A, Pitta P (2012) Marine microbial diversity and its role in ecosystem functioning and environmental change marine board position paper 17. Calewaert JB, McDonough N (eds) Marine Board-ESF, Ostend, Belgium

Hentschel U, Fieseler I, Wehrl M, Gernert C, Steinert M, Hacker J, Horn M (2003) Microbial diversity of marine sponges. In:
Muller WEG (ed) Marine molecular biotechnology. Springer, Berlin, pp 59-88

Imada C (2004) Enzyme inhibitors of marine microbial origin with pharmaceutical importance. Mar Biotechnol 6:193-198

Isnansetyo A, Kamei Y (2003) Pseudoalteromonas phenolica sp. nov., a novel marine bacterium that produces phenolic antimethicillin-resistant Staphylococcus aureus substances. Int J Syst Evol Microbiol 53(2):583-588. doi:10.1099/ijs.0.02431-0

Jayanth K, Jevasekaran G, Shakila RJ (2001) Biocontrol of fish bacterial pathogens by the antagonistic bacteria isolated from the coastal waters of Gulf of Mannar, India. Bull Eur Ass Fish Pathol 21(1):12-18

Jensen PR, Fenical W (2000) Marine microorganisms and drug discovery: current status and future potential. In: Fusetani N (ed) Drugs from the sea. S. Kruger Publishing, Basel, pp 6-29

Kiranmayi UM, Sudhakar P, Krishna N, Yellamanda B, Vijayalakshmi M (2011) Taxonomic characterization of potential bioactive metabolite producing actinomycetes from mangrove sediments of Coringa. J Pharm Res 4:4650-4653

Leon J, Liza L, Soto I, Torres M, Orosco A (2010) Marine Bacteria producing antibacterial compounds isolated from intertidal invertebrates. Rev Peru Med Exp Salud Publica 27(2):215-221

Marinho PR, Moreira AP, Pellegrino FL, Muricy G, Bastos Mdo C, Santos KR, Giambiagi-de Marval M, Laport MS (2009) Marine Pseudomonas putida: a potential source of antimicrobial substance against antibiotic resistant bacteria. Mem Inst Oswaldo Cruz 104(5):678-682

Mondol MAM, Shin HJ, Islam MT (2013) Diversity of secondary metabolites from marine Bacillus species: chemistry and biological activity. Mar Drugs 11(8):2846-2872. doi:10.3390/ md1 1082846

Nithya C, Devi MG, Pandian KS (2011) A novel compound from marine bacterium Bacillus pumilus S6-15 inhibits biofilm formation in gram-positive and gram-negative species. Boufouling 27(5):519-528. doi:10.1080/0892-7014.2011.586127

O'Brien A, Sharp R, Russel NJ, Roller S (2004) Antarctic Bacteria inhibit growth of food-borne microorganisms at low temperatures. FEMS Microbiol Ecol 48:157-167. doi:10.1016/j.femsec. 2004.01.001

Olano C, Mendez C, Salas JA (2009) Antitumour compounds from marine actinomycetes. Mar Drugs 7(2):210-248. doi:10.3390/ md7020210

Pham HT, Nguyen NP, Phi TQ, Dang PT, Le HG (2014) The antibacterial and anticancer activity of marine Actinomycete strain HP411 isolated in the Northern Coast of Vietnam. Int J Med Health Biomed Bioeng Pharm Eng 8(12):827-829

Quadri RS, Asgar D (2012) Detection of melanin producing thermoalkaliphilic Streptomyces from limestone quarries of the Deccan traps. World J Sci Technol 2:08-12

Radhakrishna E, Kumar PS, Sujatha P (2011) Optimization of marine sponge isolated bacterium Bacillus subtilis (MTCC No. 10619) for the production of antimicrobial metabolites. Asian J Chem 23(6):2779-2781

Rusch DB, Halpern AL, Sutton G, Heidelberg KB, Williamson S et al (2007) The Sorcer 11 Global ocean sampling expedition: northwest Atlantic through Eastern Tropical Pacific. PLoS Biol 5(3):e77. doi:10.1371/journal.pbio.0050077

Soliev AB, Hosokawa K, Enomoto K (2011) Bioactive pigments from marine bacteria: applications and physiological roles. Evid Based Complementary Alternat Med. doi:10.1155/2011/670349

Strobel G, Daisy B (2003) Bioprospecting for microbial endophytes and their natural products. Microbiol Mol Rev 64(7):491-502. doi:10.1128/MMBR.67.4.491-502.2003

Supriya JS, Yogesh SC (2010) Marine: the ultimate source of bioactives and drug metabolites. Int $\mathbf{J}$ Res Ayurveda Pharm 1(1):55-62 
Tawiah AA, Gbedema SY, Adu F, Roamah VE, Annan K (2012) Antibiotic producing microorganisms from River Wiwi, Lake Bosomtwe and the Gulf of Guinea at Doakor Sea Beach, Ghana. BMC Microbiol 12:234. doi:10.1186/1471-2180-12-234

Thakur AN, Thakur NI, Indap MM, Pandit RA, Datar VV, Muller WEG (2005a) Antiangiogenic, antimicrobial and cytotoxic potential of Sponge-associated bacteria. Mar Biotechnol 7(3): 245-252

Thakur NL, Thakur AN, Mueller WEG (2005b) Importance of marine natural products in drug discovery. Natural Product Radiance 46:471-477 